\title{
Diel vertical migration patterns in two populations of Chaoborus flavicans larvae (Diptera: Chaoboridae) in response to fish kairomones
}

\author{
Shigeto ODA* and Takayuki HANAZATO ${ }^{1)}$ \\ National Institute for Environmental Studies, 16-2 Onogawa, Tsukuba, Ibaraki 305-8506, Japan \\ ${ }^{1)}$ Research and Education Centre for Inlandwater Environment, Shinshu University, 5-2-4 Kogandori, Suwa 392-0027, Japan \\ *e-mail corresponding author: oda.shigeto@nies.go.jp
}

\begin{abstract}
Diel vertical migration (DVM) of larvae of the phantom midge Chaoborus flavicans (Diptera: Chaoboridae) inhabiting a fishless pond and a fish-abundant lake (Lake Nakanuma) was studied in the field and in the laboratory. In the fishless pond, dissolved oxygen concentration and water temperature were homogeneously distributed in the vertical profiles and Chaoborus larvae did not show DVM. In contrast, there was thermal stratification and an anoxic layer in Lake Nakanuma, and $2^{\text {nd }}, 3^{\text {rd }}$ and $4^{\text {th }}$ instar Chaoborus larvae exhibited DVM. Fourth instar Chaoborus larvae collected from the two populations were introduced into thermally stratified acrylic tubes containing 'fish water' (water conditioned by fish and containing only the fish 'smell') or control water free of fish smell after a two-day acclimatization, and the larval positions in the tubes were analysed during the day and at night. The two populations of Chaoborus larvae showed different DVM patterns in the control water: the larvae from Lake Nakanuma exhibited DVM, whereas those from the fishless pond did not. Chaoborus larvae from Lake Nakanuma responded to the fish kairomones, exhibiting marked DVM in the fish water, whereas little response to the fish smell was recognized in the larvae from the fishless pond. The presence of a difference in response between the two populations implies that they had genetically different patterns of expression of DVM and thus different behavioural responses to the fish smell. The fish smell tended to cause the Chaoborus larvae in the tubes to increase their depth, during both the day and night. The effects of the fish smell became ambiguous with time, suggesting microbial degradation of the fish kairomones.
\end{abstract}

Key words: bluegill sunfish, phenotypic plasticity, predator avoidance

\section{INTRODUCTION}

Diel vertical migration (DVM) is a widespread phenomenon in zooplankton and phytoplankton in both freshwater and marine environments. Most zooplankton migrate to deeper layers at around dawn and swim up again at dusk, whereas some exhibit a reverse pattern (Ohman et al. 1983).

Many hypotheses have been proposed to explain the adaptive significance of DVM (Lampert 1989, 1993), such as metabolic and demographic advantages (McLaren 1963, 1974), population energy conservation (Geller 1986), optimal resource utilization (Enright 1977), a direct deleterious effect of light (Siebeck 1978, cited in Lampert 1989), and predator avoidance (Zaret $\&$ Suffern 1976). The most dominant hypothesis today is that of predator avoidance. Zooplankton can reduce their predation risk from visually hunting predators (fish) if they stay in the deep and dark strata during the day. However, migrating to deeper layers is disadvantageous to zooplankton because there are reduced growth rates at the cold temperatures and low food levels in these layers, and there is a swimming cost. Therefore, when night comes, zooplankton migrate upward to compensate for these disadvantages of the deeper layers by spending the night in the warm and food-rich conditions of the surface water.
Various environmental factors such as temperature change, thermoclines, turbidity, food distribution, and food abundance can modify the DVM pattern (LaRow 1970; Calaban \& Makarewicz 1982; Gerritsen 1982; Johnsen \& Jakobsen 1987; Pijanowska \& Dawidowicz 1987; Dodson 1990; Leibold 1990). Moreover, relative changes in light intensity and chemical substances exuded by predators (the predators' "smell") are known to be proximate factors in the initiation and direction of DVM (Dodson 1988; Loose, von Elert \& Dawidowicz 1993). These chemical substances are called kairomones because the prey species (the receiver of the kairomone) can benefit by using them to signal information about the presence of the predator (the chemical releaser), whereas the predator receives no benefit (Brown et al. 1970). Various vertebrate (fish) and invertebrate (rotifers, copepods, and backswimmer and phantom midge larvae) predators release kairomones, which induce changes in the morphology, life history traits, and behaviour of zooplankton (Larsson \& Dodson 1993; Hanazato 1994).

Larvae of the phantom midge Chaoborus (Diptera: Chaoboridae) often occur as major zooplankton in eutrophic lakes and ponds. The larvae, especially $3^{\text {rd }}$ and $4^{\text {th }}$ instars, show marked DVM in environments with abundant fish (Stahl 1966; Teraguchi \& Northcote 1966; Goldspink \& Scott 1971; Luecke 1986), but not in environments with no or few fish (Northcote 1964; 
Carter \& Kwik 1977; Luecke 1986). This suggests that the presence of fish is a factor that induces DVM. Laboratory studies have indicated that kairomones released from fish induce DVM of $4^{\text {th }}$ instar $C$. flavicans larvae (Dawidowicz et al. 1990; Dawidowicz 1993).

We analysed the effects of fish kairomones ("smell") on the DVM behaviour of C. flavicans larvae in two populations - one in a fishless pond and one in a fishabundant lake - that seemed to have different responses to fish smell. In the laboratory we compared the DVM patterns of the larvae from these two populations in the presence or absence of fish smell.

\section{METHODS}

\subsection{Analysis of DVM of Chaoborus larvae in the field}

The fishless pond was located in the grounds of the National Institute for Environmental Studies (NIES, Tsukuba, Ibaraki, Japan; $\left.36^{\circ} 02^{\prime} \mathrm{N}, 140^{\circ} 07^{\prime} \mathrm{E}\right)$. This eutrophic fish-free pond (maximum depth $4.2 \mathrm{~m}$; surface area $3890 \mathrm{~m}^{2}$ ) was constructed by digging in a wetland in 1980. Chaoborus flavicans is one of the major invertebrates in the pond, and the population has been reported to produce 10 complete and one incomplete cohort annually (Iwakuma et al. 1989).

Lake Nakanuma (Ryugasaki, Ibaraki, Japan; $35^{\circ} 53^{\prime} \mathrm{N}, 140^{\circ} 09^{\prime} \mathrm{E}$ ) is a small eutrophic lowland lake (maximum depth $13 \mathrm{~m}$; surface area $1.08 \mathrm{ha}$ ) that develops thermal stratification in summer. The lake is inhabited by a planktivorous fish, the bluegill sunfish (Lepomis macrochirus), and by C. flavicans larvae, which exhibit marked DVM (Hanazato 1992).

The vertical distributions of Chaoborus larvae in the fishless pond and in Lake Nakanuma were investigated by taking a series of discrete depth samples at the centre of each water body at noon (12:00) and at midnight $(0: 00)$. In the fishless pond, sampling was conducted at depths of $0,1,2$, and $3 \mathrm{~m}$ on 7 October 1994. Larvae were collected by passing $12 \mathrm{~L}$ water samples through a $40 \mu \mathrm{m}$ mesh net; two samples were taken at each depth with a 6.0 L Van Dorn sampler (Rigosha Co., Ltd., Saitama, Japan). The larvae in Lake Nakanuma were collected on 18 October 1994 by hauling a conical closing net ( $1 \mathrm{~m}$ long; $30 \mathrm{~cm}$-diameter opening; $200 \mu \mathrm{m}$ mesh) vertically for a distance of $2 \mathrm{~m}$ at $2 \mathrm{~m}$ intervals from the surface to $10 \mathrm{~m}$ depth. Samples at a depth of 10 to $12 \mathrm{~m}$ could not be collected because they contained too much mud. Larvae were preserved in 5\% formalin solution. Larval instars were identified from the head capsule width as a criterion of instar separation and were counted under a dissecting microscope in the laboratory.

At the time of sampling, the temperature and oxygen concentration profiles of the water column were determined by means of a YSI model 54A oxygen meter (YSI Hydrodata Ltd., Hertfordshire, UK) in Lake Nakanuma and a YSI model 55 oxygen meter (YSI Hydrodata Ltd., Hertfordshire, UK) in the fishless pond.

\subsection{Experimental analysis of DVM of Chaoborus larvae}

\subsubsection{Collection of larvae}

All the experiments were carried out on 4th instar larvae of $C$. flavicans collected from the fishless pond and Lake Nakanuma in July 1994. The larvae were collected during the day by towing a plankton net $(40 \mathrm{~cm}$ diameter opening, $300 \mu \mathrm{m}$ mesh) from the bottom to the surface of the pond and the lake. They were then kept in an aquarium containing aged tap water at $20^{\circ} \mathrm{C}$ under a 16:8 light:dark cycle for 2 days before the experiments. Neonates of the cladoceran Moina macrocopa were supplied as food.

\subsubsection{Experimental apparatus}

The experimental apparatus consisted of 30 clear acrylic tubes ( $1 \mathrm{~m}$ long, $3.0 \mathrm{~cm}$ in diameter) placed vertically in a transparent acrylic water bath $(13 \times 60 \times 60$ $\mathrm{cm})$. This apparatus was set in a temperature-controlled room $\left(23^{\circ} \mathrm{C}\right)$ under a $16: 8$ light:dark cycle. The room was illuminated homogeneously with fluorescent lamps on the ceiling. At the start of the experiments, the larvae were put into the tubes, which had been marked with ticks at $10 \mathrm{~cm}$ intervals from the top to the bottom for measurement of larval depth, and had been filled with test medium. The water temperature in the lower halves of the tubes was reduced to form a thermal stratification of the water column by cooling the water bath with a thermoregulator (TAIYO Cool Mix, TAITECH Co., Ltd., Japan).

To form a light gradient in the tubes that was similar to the one present in the field, the acrylic water bath was covered with black vinyl sheeting to shield the lower half of the tubes from light. The black sheet had windows on both sides of the water bath for observation of the larvae in the lower parts of the tubes.

Swift \& Forward (1980) reported that 4th instar Chaoborus punctipennis larvae respond weakly to red light. Therefore, we used a dim red fluorescent lamp to track DVM behaviour in the tubes during the dark period.

The larvae in the tubes were fed with the small cladoceran Moina micrura, which had been cultured at $20{ }^{\circ} \mathrm{C}$ under a 16:8 light:dark regime. Between 20 and 30 moinids were put into each tube just before the start of the dark period every day. Most of the prey animals were distributed in the upper, warmer parts (i.e., the epilimnion) of the tubes.

\subsubsection{Experimental design}

The larvae were put into tubes containing either control water or fish-conditioned water (fish water). Aged tap water in which fish had never been reared was used as the control water. The fish water was prepared as follows. Bluegill sunfish (body length: 13 to $14 \mathrm{~cm}$ ) were reared individually for 2 or 3 days in $10 \mathrm{~L}$ aquaria 


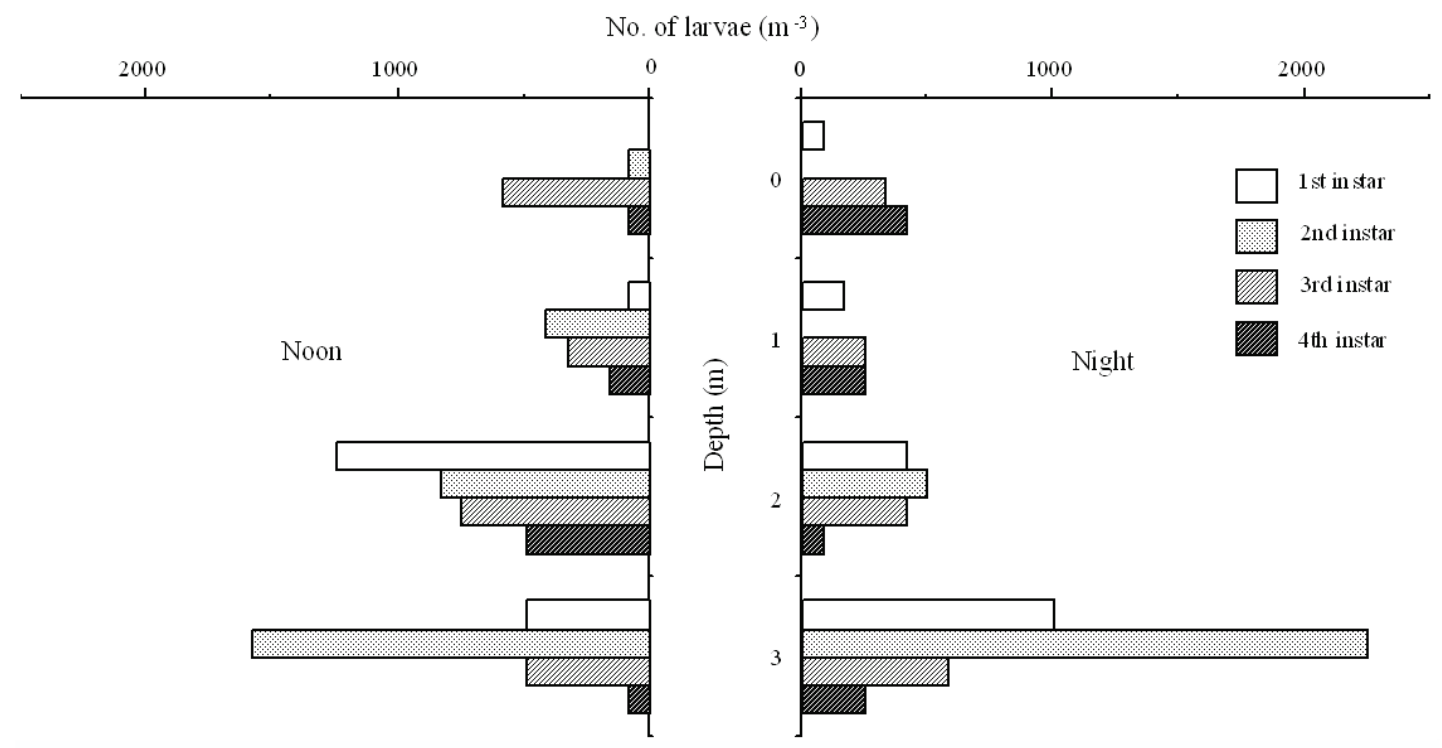

Fig. 1. Vertical distribution of Chaoborus larvae in the fishless pond at noon (left) and midnight (right) on 7 October 1994.

filled with aged tap water. Adequate amounts of the cladoceran Daphnia magna were provided daily as food. At the end of the rearing period the water was filtered with a Whatman GF/C filter to remove any particles $>1 \mu \mathrm{m}$ in diameter. The fish water was prepared just before the start of each experiment and was never replenished during the experimental period.

The following two experiments were conducted to analyse the DVM behaviour of the Chaoborus larvae from the fishless pond and Lake Nakanuma under conditions with or without fish smell.

In experiment 1, larvae from the two populations were kept in the tubes containing the control water or fish water at a density of one individual per tube, with a light gradient and thermal stratification $\left(20.3^{\circ} \mathrm{C}\right.$ at the surface and $12.9{ }^{\circ} \mathrm{C}$ at the bottom). Seven replicates were prepared for each of four treatments (two populations $\times$ two culture media). The experiment was conducted for 4 days. Positions of the individuals were recorded every $3 \mathrm{~h}$ in the daytime (10:00, 13:00, 16:00, 19:00, and 22:00) and twice each night (1:00 and 6:00).

In experiment 2 , each treatment had four replicates and the larval density was five individuals per tube. Both a light gradient and thermal stratification were formed. The depths of the larvae in the tubes were recorded once in the daytime (16:00) and once at night (4:00), and the observation was continued for 5 days.

\section{RESULTS}

\subsection{Field data}

In the fishless pond, the profiles of water temperature at noon (12:00) and at midnight (0:00) were almost the same, except at the surface, where the temperatures were $23.1{ }^{\circ} \mathrm{C}$ (noon) and $21.8{ }^{\circ} \mathrm{C}$ (midnight). The dissolved oxygen concentration, which was $4.56 \mathrm{mg} \mathrm{L}^{-1}$ at $0 \mathrm{~m}$, decreased gradually to $2.51 \mathrm{mg} \mathrm{L}^{-1}$ near the bottom at $3.5 \mathrm{~m}$ and did not show any marked difference between noon and midnight.

Figure 1 shows the vertical distribution of $C$. flavicans larvae in the fishless pond. There was no marked difference in the profiles of the $3^{\text {rd }}$ and $4^{\text {th }}$ instar larval vertical distribution in the fishless pond in between 12:00 and at 0:00 (Fisher's exact probability test, $P=0.24$, Sokal \& Rohlf 1995). The larvae tended to be distributed throughout the whole water column.

A marked thermocline was present in Lake Nakanuma at around $9 \mathrm{~m}$ depth. The water temperature of the epilimnion was about $22{ }^{\circ} \mathrm{C}$ and that of the hypolimnion $10{ }^{\circ} \mathrm{C}$. The lower layers of the hypolimnion were anoxic; the dissolved oxygen concentration was $<3 \mathrm{mg} \mathrm{L}^{-1}$ below $8 \mathrm{~m}$ depth. Differences in water temperature or dissolved oxygen were not observed between noon and midnight.

Because larval samples were not collected from the stratum below $10 \mathrm{~m}$ depth in Lake Nakanuma, there are no data on the density of larvae in that stratum. However, in the water column above $10 \mathrm{~m}$ depth, the vertical profile of Chaoborus larvae at noon significantly differed from that at midnight (Fisher's exact probability test, $P<0.001$, Sokal \& Rohlf 1995). The larvae stayed in the low-oxygen layer ( 8 to $10 \mathrm{~m}$ ) at noon, whereas they went up to $4 \mathrm{~m}$ depth at midnight and were not observed in the 8 - to $10 \mathrm{~m}$ stratum (Fig. 2). The results indicate that Chaoborus larvae performed DVM in the lake.

\subsection{DVM of Chaoborus larvae in experimental tubes}

\subsubsection{Experiment 1: one larva per tube}

Lack of normal DVM behaviour (up at night and down during the day) by the larvae from the fishless pond was observed in both the control water and the fish water (Fig. 3a, Mann-Whitney U-test). Rather, the lar- 


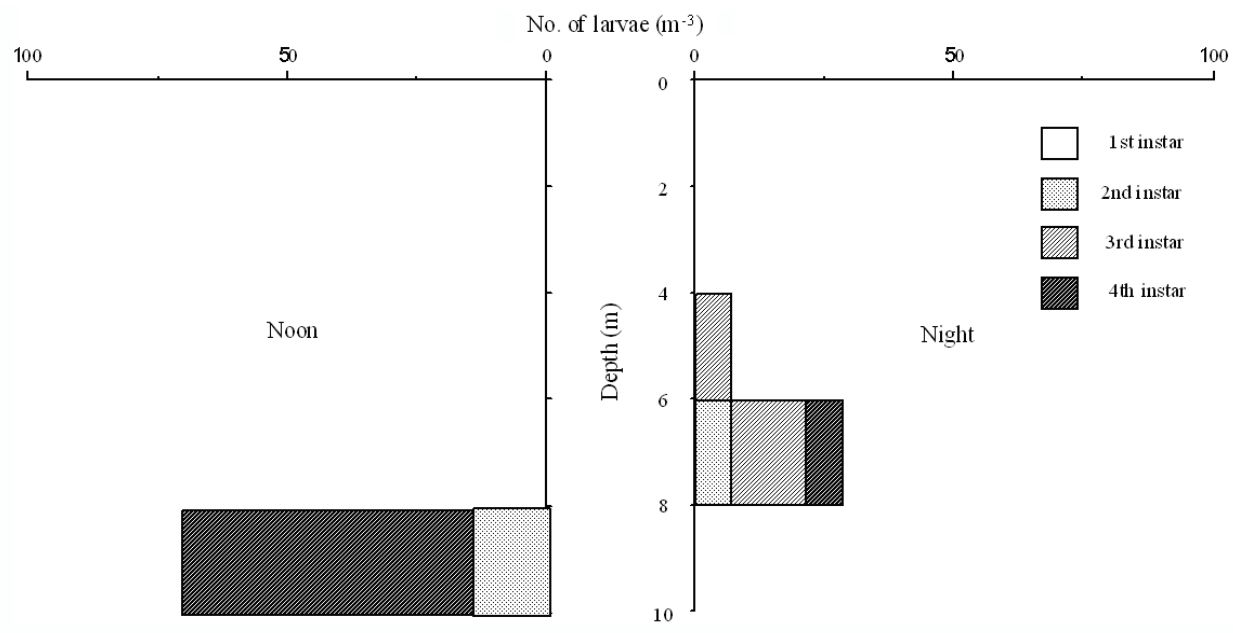

Fig. 2. Vertical distribution of Chaoborus larvae in Lake Nakanuma at noon (left) and midnight (right) on 18 October 1994.
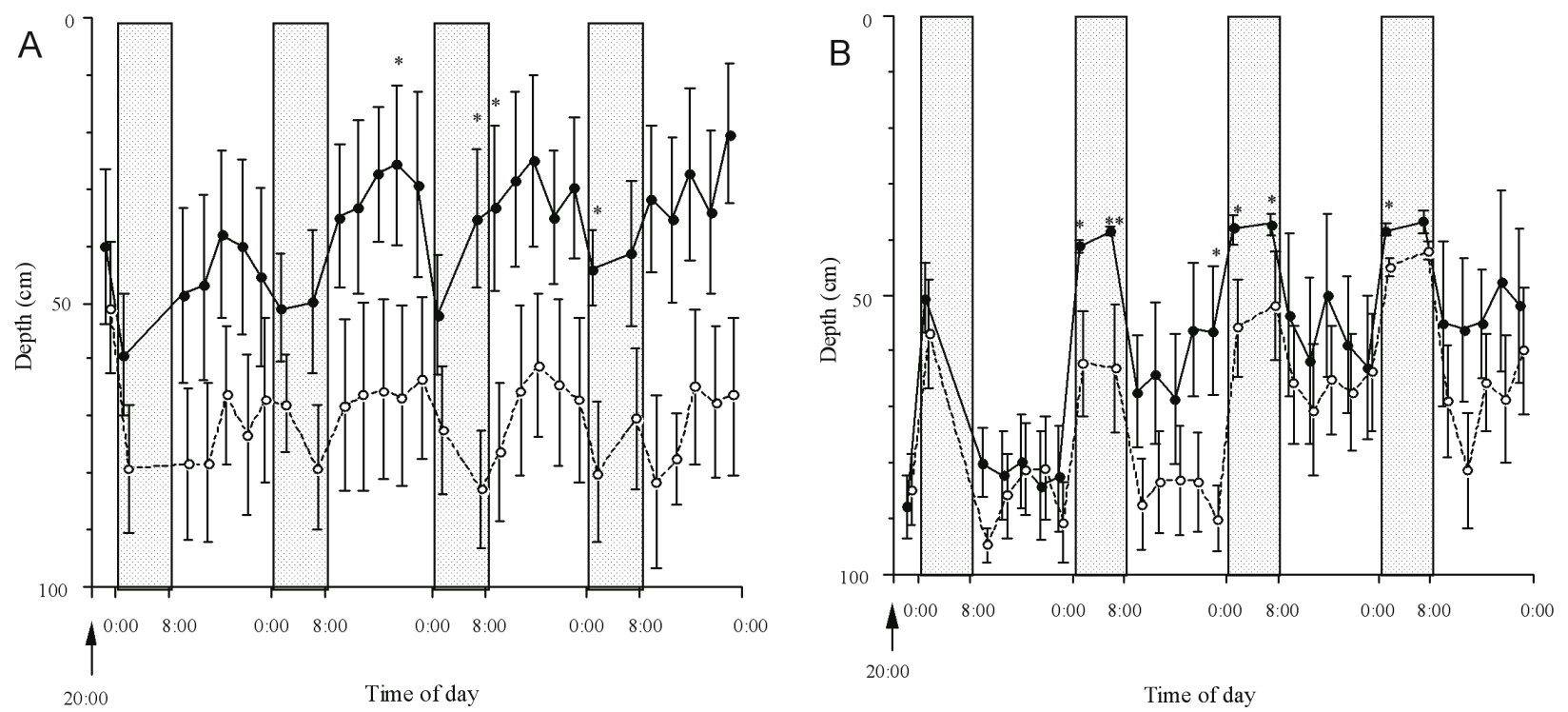

Fig. 3. Mean depths ( $\pm \mathrm{SE}, \mathrm{N}=7$ at the start) of larvae (A) from the fishless pond and (B) from Lake Nakanuma in the tubes containing control water (closed circles) and fish water (open circles) in Experiment 1. Shaded areas are periods of darkness. Asterisks indicate significant differences in the larval depths between the control water and fish water $($ Mann-Whitney $\mathrm{U}$-test, $*=P$ $<0.05, * *=P<0.01)$. When the experiment ended more than $85 \%$ of the larvae remained.

vae slightly showed a reverse pattern. Although the fish water did not induce DVM by the larvae, it lowered the larval positions in the tubes; their positions were significantly deeper in the fish water than in the control water at times (Fig. 3a, Mann-Whitney U-test, $*=P<0.05, * *$ $=P<0.01$ ).

The larvae from Lake Nakanuma exhibited DVM patterns in both the control water (Mann-Whitney Utest, $P<0.001$ ) and the fish water (Mann-Whitney Utest, $P<0.001)$, and they stayed deeper in the fish water than in the control water (Fig. 3b). Larval depths between the control water and fish water were significantly different at times (Mann-Whitney U-test, $*=P$ $<0.05, * *=P<0.01)$.

\subsubsection{Experiment 2: five larvae per tube}

When there were five larvae in each tube, the larvae from the fishless pond again did not exhibit significant DVM behaviour in the control water or the fish water (insignificant day-night effect by ANOVA with repeated measurements), and there was no clear difference in their mean depths in the two types of water (Fig. $4 \mathrm{a}$, ANOVA with repeated measurements, $P=0.27$ ). By contrast, the larvae from Lake Nakanuma exhibited a definite DVM pattern in the fish water (ANOVA with repeated measurements, $\mathrm{P}<0.001)$, but not in the control water $(P=0.99$, Fig. $4 \mathrm{~b})$. The mean larval depths in the two types of water did not differ significantly 

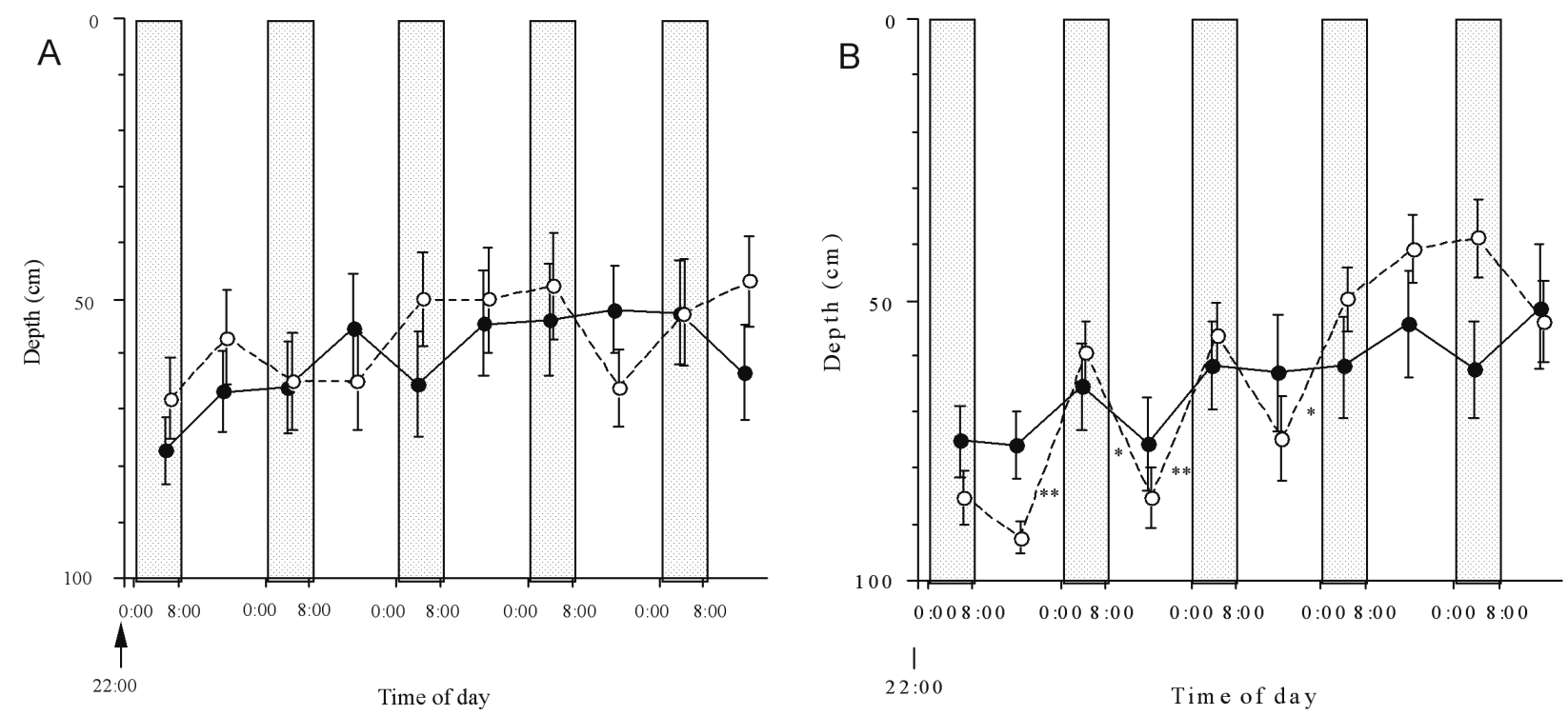

Fig. 4. Mean depths ( \pm SE, $N=20$ at the start) of larvae (A) from the fishless pond and (B) from Lake Nakanuma in the tubes containing control water (closed circles) and fish water (open circles) in Experiment 2. Shaded areas are periods of darkness. Asterisks indicate significant differences in the larval depths between adjacent measurements either in the control water or fish water (Mann-Whitney U-test, $*=P<0.05$, ** $=P<0.01$ ). See Results for the results of Anova. When the experiment ended more than $65 \%$ of the larvae remained.

(ANOVA with repeated measurements, $P=0.73$, Fig. $4 b$ ). All of the DVM behaviour (as expressed by average depth) occurred in the lower halves of the tubes (in the hypolimnion). As the experiment proceeded, the position of the larvae at noon gradually shifted upward and the amplitude of the vertical migration became smaller (Fig. 4b).

\section{DISCUSSION}

It is widely known that chemical substances exuded by fish induce DVM behaviour in Chaoborus larvae and Daphnia (Tjossem 1990; Dawidowicz 1993; Loose et al. 1993). In our experiments, DVM behaviour was induced by a fish (bluegill) kairomone in Chaoborus larvae from Lake Nakanuma (Figs $3 b$ and $4 b$ ). The kairomone may be a proximate factor that induces DVM by Chaoborus larvae in the lake.

The fish smell tended to cause the Chaoborus larvae to stay deeper in the experimental tubes at both noon and midnight (Figs $3 \mathrm{~b}$ and $4 \mathrm{~b}$ ). A similar finding was obtained in C. flavicans by Dawidowicz et al. (1990). From the standpoint of adaptive significance, however, all that the larvae have to do is to increase their depths only during the day in response to the fish smell, because larvae can reduce their vulnerability to predation by spending only the daytime in the deep and dark layer, where visually oriented planktivorous fish can hardly detect their prey. It is probable that, under our experimental conditions, the larvae responded to the fish kairomone even in the night phase. Loose and Dawidowicz (1994) demonstrated that D. magna exposed to higher concentrations of fish kairomone exhibit greater DVM response and stay deeper even at night, suggesting that the degree of DVM response depends on the kairomone concentration, as is the case in the morphological response of Daphnia to different concentrations of predator kairomone (Parejko \& Dodson 1991). Therefore, if Chaoborus larvae are exposed to high concentrations of fish kairomones in natural environments, they could suffer from a lack of food if they were to stay in the food-poor strata during both the day and night.

The larvae from Lake Nakanuma exhibited marked DVM in the fish water, but the pattern became more ambiguous as time passed (Figs $3 \mathrm{~b}$ and $4 \mathrm{~b}$ ). This is presumably because, in part, the kairomone exuded by the bluegill sunfish lost its effect in a few days owing to degradation by microbes. Loose et al. (1993) studied the induction of DVM in D. magna by kairomones released from fish (Leucaspius delineatus, Cyprinidae) and found that the activity of the kairomones disappeared within $24 \mathrm{~h}$ under non-sterile conditions at $37{ }^{\circ} \mathrm{C}$, suggesting that microbial degradation of the kairomones occurred.

The larvae from the fishless pond did not show marked DVM behaviour, either in the control water or in the fish water. Why did DVM differ between the population from Lake Nakanuma and that from the fishless pond? This can be explained by the fact that the larvae in the two populations had DVM traits that were genetically based and differed in their degree of phenotypic plasticity.

Daphnia are known to exhibit varying degrees of DVM, with a genetic component, in the absence of predators (Weider 1984; Watt \& Young 1992; De 
Meester 1993). Our larvae from the fishless pond did not exhibit DVM in the control water, whereas those from Lake Nakanuma did in the same water. This could be attributed to the fact that the Chaoborus larvae in the two populations have different genetically based DVM patterns. However, we must note the possibility that habituation of the larvae to their natural environments, with or without fish predation, persisted during the experiments despite prior acclimatization.

The different responses of Chaoborus larvae to kairomones suggest that the larvae have varying degrees of phenotypic plasticity in their DVM behaviour in response to different predation regimes. Daphnia, for example, exhibit a variety of responses (changes in morphology, life history traits, and DVM behaviour) when they are exposed to predators' kairomones, and Daphnia that occur in environments with abundant predators tend to be more sensitive to kairomones than those in environments with fewer predators (Parejko \& Dodson 1991; Lüning 1992; Spitze 1992; Black 1993; De Meester 1993).

Adult phantom midges migrate to lakes and ponds to lay eggs and their larvae are exposed to unpredictable predation pressure that varies seasonally and among water bodies. Therefore, it should be adaptively important for Chaoborus larvae to have the ability to detect the presence of predators and to avoid predation behaviourally only when it is necessary. However, the poor response of our larvae from the fishless pond to the fish smell suggests that gene flow mediated by adults migrating between neighbouring populations of $C$. flavicans is limited. The environmental conditions (e.g., distance between water bodies) that limit the gene flow should be analysed in future studies.

Chaoborus flavicans in Lake Nakanuma are reported to produce fewer generations in a year than those in the fishless pond (Iwakuma et al. 1989; Iwakuma, unpublished data). In part, this is because the larvae in the lake migrate into the cold anoxic layer with little food in the daytime to reduce the predation risk, and this activity probably retards their development. Dawidowicz (1993) studied the DVM of $4^{\text {th }}$ instar $C$. flavicans larvae introduced individually into thermally stratified tubes and found that DVM retarded larval development rates. Similar results were obtained in Daphnia by Stich \& Lampert (1984), Dawidowicz \& Loose (1992), and Loose \& Dawidowicz (1994). They studied the life history parameters of Daphnia species under food supply and temperature conditions that simulated those that might be experienced by Daphnia exhibiting DVM. It is possible, therefore, that fish kairomones affect the population dynamics of Chaoborus by controlling larval behaviour.

\section{ACKNOWLEDGMENTS}

We thank Prof. Minoru Murai in Tropical Biosphere Research Center, University of the Ryukyus, Japan for his valuable suggestions and improvement of the manuscript. Thanks are also due to the staff of Kawakami Farm, Inc., including S. Karube, K. Kawabe, Y. Ogamino, and F. Ohyama, for their help with the experiments in the laboratory.

\section{REFERENCES}

Black, A.R. 1993. Predator-induced phenotypic plasticity in Daphnia pulex: life history and morphological responses to Notonecta and Chaoborus. Limnol. Oceanogr., 38: 986-996.

Brown, W.L. Jr., T. Eisner \& R.H. Whittaker. 1970. Allomones and kairomones: transspecific chemical messengers. BioScience, 20: 21-22.

Calaban, M.J. \& J.C. Makarewicz. 1982. The effect of temperature and density on the amplitude of vertical migration of Daphnia magna. Limnol. Oceanogr., 27: 262-271.

Carter, J.C.H. \& J.K. Kwik. 1977. Instar succession, vertical distribution, and interspecific competition among four species of Chaoborus. J. Fish. Res. Board Can., 34: 113118.

Dawidowicz, P. 1993. Diel vertical migration in Chaoborus flavicans: population pattern $v s$ individual tracks. Arch. Hydrobiol., 39: 19-28.

Dawidowicz, P. \& C. Loose. 1992. Metabolic costs during predator-induced diel vertical migration of Daphnia. Limnol. Oceanogr., 37: 1589-1595.

Dawidowicz, P., J. Pijanowska \& K. Ciechomski. 1990. Vertical migration of Chaoborus larvae is induced by the presence of fish. Limnol. Oceanogr., 35: 1631-1637.

De Meester, L. 1993. Genotype, fish-mediated chemicals, and phototactic behavior in Daphnia magna. Ecology, 74: 1467-1474.

Dodson, S.I. 1988. The ecological role of chemical stimuli for the zooplankton: predator-avoidance behavior in Daphnia. Limnol. Oceanogr., 33:1 431-1439.

Dodson, S.I. 1990. Predicting diel vertical migration of zooplankton. Limnol. Oceanogr., 35: 1195-1200.

Enright, J.T. 1977. Diurnal vertical migration: adaptive significance and timing. Part 1 . Selective advantage: a metabolic model. Limnol. Oceanogr., 22: 856-872.

Geller, W. 1986. Diurnal vertical migration of zooplankton in a temperate great lake (L. Constance): a starvation avoidance mechanism? Arch. Hydrobiol. Suppl., 74: 1-60.

Gerritsen, J. 1982. Behavioral response of Daphnia to rate of temperature change: possible enhancement of vertical migration. Limnol. Oceanogr., 27: 254-261.

Goldspink, C.R. \& D.B.C Scott. 1971. Vertical migration of Chaoborus flavicans in a Scottish loch. Freshwat. Biol., 1: 411-421.

Hanazato, T. 1992. Direct and indirect effects of low-oxygen layers on lake zooplankton communities. Arch. Hydrobiol., 35: 87-98.

Hanazato, T. 1994. Kairomone-mediated predator-prey relationship in lake zooplankton communities. Jpn. J. Ecology, 44: 61-77 (In Japanese with English summary).

Iwakuma, T., K. Shibata \& T. Hanazato. 1989. Production ecology of phyto- and zooplankton in a eutrophic pond dominated by Chaoborus flavicans (Diptera: Chaoboridae). Ecol. Res., 4: 31-53.

Johnsen, G.H. \& P.J. Jakobsen. 1987. The effect of food limitation on vertical migration in Daphnia longispina. Limnol. Oceanogr., 32: 873-880.

Lampert, W. 1989. The adaptive significance of diel vertical migration of zooplankton. Funct. Ecol., 3: 21-27.

Lampert, W. 1993. Ultimate causes of diel vertical migration of zooplankton: New evidence for the predator-avoidance hypothesis. Arch. Hydrobiol., 39: 79-88. 
LaRow, E.J. 1970. The effect of oxygen tension on the vertical migration of Chaoborus larvae. Limnol. Oceanogr., 15: 357-362.

Larsson, P. \& S.I. Dodson. 1993. Chemical communication in planktonic animals. Arch. Hydrobiol., 129: 129-155.

Leibold, M.A. 1990. Resources and predators can affect the vertical distributions of zooplankton. Limnol. Oceanogr., 35: 938-944.

Loose, C.J. \& P. Dawidowicz. 1994. Trade-off in diel vertical migration by zooplankton: the costs of predator avoidance. Ecology, 75: 2255-2263.

Loose, C.J., E. von Elert \& P. Dawidowicz. 1993. Chemicallyinduced diel vertical migration in Daphnia: a new bioassay for kairomones exuded by fish. Arch. Hydrobiol., 126: 329-337.

Luecke, C. 1986. A change in the pattern of vertical migration of Chaoborus flavicans after the introduction of trout. $J$. Plankton Res., 8: 649-657.

Lüning, J. 1992. Phenotypic plasticity of Daphnia pulex in the presence of invertebrate predators: morphological and life history responses. Oecologia, 92: 383-390.

McLaren, I.A. 1963. Effects of temperature on growth of zooplankton, and the adaptive value of vertical migration. $J$. Fish Res. Board Can., 20: 685-727.

McLaren, I.A. 1974. Demographic strategy of vertical migration by a marine copepod. Am. Nat., 108: 91-102.

Northcote, T.G. 1964. Use of high-frequency echo sounder to record distribution and migration of Chaoborus larvae. Limnol. Oceanogr., 9: 87-91.

Ohman, M.D., B.W. Frost \& E.H. Cohen. 1983. Reverse diel vertical migration: an escape from invertebrate predators. Science, 220: 1404-1407.

Received: April 2008

Accepted: June 2008
Parejko, K. \& S.I. Dodson. 1991. The evolutionary ecology of an antipredator reaction norm: Daphnia pulex and Chaoborus americanus. Evolution, 45: 1665-1674.

Pijanowska, J. \& P. Dawidowicz. 1987. The lack of vertical migration in Daphnia: the effect of homogeneously distributed food. Hydrobiologia, 148: 175-181.

Sokal, R.R. \& F.J. Rohlf (Eds). 1995. Biometry. 3rd ed. WH Freeman and Company, New York.

Spitze, K. 1992. Predator mediated plasticity of prey life history and morphology: Chaoborus americanus predation on Daphnia pulex. Am. Nat., 139: 229-247.

Stahl, J.B. 1966. The ecology of Chaoborus in Meyers Lake, Indiana. Limnol. Oceanogr., 11: 177-183.

Stich, H.B. \& W. Lampert. 1984. Growth and reproduction of migrating and non-migrating Daphnia species under simulated food and temperature conditions of diurnal vertical migration. Oecologia, 61: 192-196.

Swift, M.C. \& R.B. Forward Jr. 1980. Photoresponses of Chaoborus larvae. J. Insect Physiol., 26: 365-371.

Teraguchi, M. \& T.G. Northcote. 1966. Vertical distribution and migration of Chaoborus flavicans larvae in Corbett Lake, British Columbia. Limnol. Oceanogr., 11: 164-176.

Tjossem, S.F. 1990. Effects of fish chemical cues on vertical migration behavior of Chaoborus. Limnol. Oceanogr., 35: 1456-1468.

Watt, P.J. \& S. Young. 1992. Genetic control of predator avoidance behaviour in Daphnia. Freshwat. Biol., 28: 363-367.

Weider, L.J. 1984. Spatial heterogeneity of Daphnia genotypes: vertical migration and habitat partitioning. Limnol. Oceanogr., 29: 225-235.

Zaret, T.M. \& J.S. Suffern. 1976. Vertical migration in zooplankton as a predator avoidance mechanism. Limnol. Oceanogr., 21: 804-813. 